\title{
Science and Language Instructional Shifts with Second-Language Learners
}

\author{
Okhee Lee \\ Corresponding author, \\ Department of Teaching and Learning, New York University, \\ New York, NY 10003, USA \\ olee@nyu.edu
}

Received: 13 July 2020 | Revised: 6 October 2020 |

Accepted: 6 November 2020

\begin{abstract}
In the United States, A Framework for K-12 Science Education (National Research Council, 2012) and Next Generation Science Standards (NGSS) offer a vision of rigorous science standards for all students across K-12 classrooms. As science and engineering practices (e.g., develop models, argue from evidence, construct explanations) are language intensive, engagement in these practices presents both language learning opportunities and demands to all students, especially second language learners. The purpose of this article is to describe science instructional shifts, spurred by the Framework and the NGSs, and language instructional shifts, informed by contemporary views in second language acquisition described in English Learners in STEM Subjects (National Academies of Sciences, Engineering, and Medicine, 2018). The article describes a yearlong fifth-grade science curriculum to illustrate how science and language instructional shifts are mutually supportive of each other to promote rigorous science learning and rich language use with a focus on second language learners.
\end{abstract}

\section{Keywords}

Next Generation Science Standards - integration of science and language - second language learners - English learners - science instructional shifts - language instructional shifts 
In the United States, A Framework for K-12 Science Education (National Research Council [NRC], 2012; shortened to the Framework hereafter) and the Next Generation Science Standards (NGSS; NG Ss Lead States, 2013a) were developed with the vision of "all standards, all students" (NGSS Lead States, 2013b; see also Lee et al., 2015). Grounded in the vision of the Framework and the NGSs, there is broad consensus around science instructional shifts in the science education community. These shifts also have the potential to create classroom communities that promote language learning for all students in science (Lee et al., 2013; Lee et al., 2019) and across STEM subjects broadly as described in English Learners in STEM Subjects (National Academies of Sciences, Engineering, and Medicine [NASEM], 2018).

Since the publication of the Framework in 2012 and the release of the NGSS in 2013, 20 states and the District of Columbia have adopted the NGSS and 24 additional states have developed their own standards based on the Framework (https://ngss.nsta.org/About.aspx). This vision for science education is taking hold in schools and classrooms across the United States, just as the student population is becoming increasingly diverse. Traditionally underrepresented groups in terms of race and ethnicity are now the majority, and English learners (ELs) make up the fastest growing subset, constituting 9.6\%, or 4.9 million students, of the pre-K-12 public school student population in the United States (National Center for Education Statistics, 2019). In addition to students currently classified as ELs, students who have exited language support services (former ELs) often continue to require instructional support.

The purpose of this article is to describe science instructional shifts, spurred by the Framework and the N Gss, and language instructional shifts, informed by contemporary views in second-language learning. These science and language instructional shifts are mutually supportive of each other to promote rigorous science learning and rich language use with all students, especially ELs.

To illustrate how science and language instructional shifts with a focus on ELs are incorporated into science curricula, the article describes the Science And Integrated Language (SAIL) curriculum, which is an NGSS-aligned yearlong fifth-grade curriculum with a focus on ELs. The SAIL curriculum capitalizes on the mutually supportive nature of science and language instructional shifts to promote rigorous science learning and rich language use with all students, especially ELs. In this article, I use the term ELs because it is the term used in federal legislation beginning with the Every Student Succeeds Act of 2015 in the United States. However, in other countries with their own educational policies and practices, other terms are used to describe second-language learners. 


\section{Science and Language Instructional Shifts with a Focus on} English Learners

Recent years have witnessed parallel shifts in science learning and secondlanguage learning. In science learning, traditional views have focused on individual learners' mastery of discrete elements of science content, whereas contemporary views emphasize that students make sense of phenomena and design solutions to problems as scientists and engineers do in their professional work (NRC, 2012). Because the contemporary approach involves using and applying knowledge for a particular purpose, it has been referred to as knowledge-in-use (Harris et al., 2016). In second-language learning, traditional views have focused on discrete elements of vocabulary (lexicon) and grammar (syntax) to be internalized by learners, whereas contemporary views emphasize that language is a set of dynamic meaning-making practices learned through participation in social contexts (Larsen-Freeman, 2007; Valdés, 2015; Zuengler \& Miller, 2006). Because the contemporary approach involves using language for a particular purpose, it has been referred to as language-in-use (Lee et al., 2013).

Two points about the EL student population need clarification. First, ELs are a heterogeneous group, comprised of students who vary widely in their backgrounds and characteristics (Kibler et al., 2014). For ease of reference, I use the term ELs to include both students currently classified as ELs (at beginning, intermediate, and advanced levels of proficiency) and former ELs, while recognizing the range of linguistic diversity that this term obscures. Second, although ELs are a central focus in this article, the language-intensive nature of the NGSS presents both opportunities and challenges for many students (Quinn et al., 2012).

\section{Science Instructional Shifts}

In the United States, Science for All Americans (American Association for the Advancement of Science [AAAS], 1989) and Benchmarks for Science Literacy (AAAS, 1993) started the standards-based reform in science education in the early 199os. These were followed by the National Science Education Standards (NRC, 1996). More recently, the Framework was published in 2012, which reflects how science changed and how our understanding of how children learn science improved. Grounded in the Framework, the NGSS were released in 2013.

The Framework and the NGss place equity at the center, and the traditional approaches gave way to more contemporary approaches (NGSS Lead States, 2013b; see also Lee et al., 2015). Traditionally, scientists and science teachers 
have defined canonical knowledge of science disciplines, which was typically presented in science textbooks. Some students learned science, but science did not make sense to many students. In contemporary views, all students are making sense of phenomena or designing solutions to problems as scientists and engineers do in their professional work.

Central to the vision of the Framework and the NGSS are three instructional shifts that work together to promote science learning with all students. These shifts include (a) explaining phenomena and designing solutions to problems, (b) engaging in three-dimensional learning, and (c) building coherent learning progressions over time.

The first shift involves explaining phenomena in the natural world (science) or designing solutions to problems in the designed world (engineering). According to the Framework and the NGSS, phenomena or problems are central to science and science learning, as "the goal of science is to develop a set of coherent and mutually consistent theoretical descriptions of the world that can provide explanations over a wide range of phenomena" (NRC, 2012, p. 48). As students use science knowledge to make sense of phenomena and figure out answers to questions, they experience the work of scientists or engineers. As students do something with science by making sense of phenomena or problems, students have a purpose for learning science. This is a key shift from traditional views that centered on students' mastery of science content.

The second shift involves three-dimensional learning by integrating science and engineering practices (SEPs), crosscutting concepts (CCCs), and disciplinary core ideas (DCIs; NRC, 2012). The three dimensions are summarized in Table 1. Below, each dimension is described in terms of what it is (NRC, 2012) and how it has evolved from the previous generation of science standards in the United States (AAAS, 1989; NRC, 1996).

SEPs describe "(a) the major practices that scientists employ as they investigate and build models and theories about the world and (b) a key set of engineering practices that engineers use as they design and build systems" (NRC, 2012, p. 30). The National Science Education Standards (NRC, 1996, 2000) emphasized science inquiry as the core of science teaching and learning, but science inquiry was criticized for being ill-defined and ambiguous. The Framework (NRC, 2012) emphasizes that students engage in science and engineering as scientists and engineers do in their professional work. SEPs represent the deepening and refinement of science inquiry.

CCCs have "applicability across science disciplines" (NRC, 2012, p. 29), offer "explanatory value throughout much of science and engineering, ... [and] provide students with an organizational framework for connecting knowledge from the various disciplines into a coherent and scientifically based view of 


\section{Scientific and engineering practices (SEPs)}

1. Asking questions (for science) and defining problems (for engineering)

2. Developing and using models

3. Planning and carrying out investigations

4. Analyzing and interpreting data

5. Using mathematics and computational thinking

6. Constructing explanations (for science) and designing solutions (for engineering)

7. Engaging in argument from evidence

8. Obtaining, evaluating, and communicating information

\section{Crosscutting concepts (CCCs)}

1. Patterns

2. Cause and effect: Mechanism and explanation

3. Scale, proportion, and quantity

4. Systems and system models

5. Energy and matter: Flows, cycles, and conservation

6. Structure and function

7. Stability and change

\section{Disciplinary core ideas (DCIs)}

Physical sciences

PS 1: Matter and its interactions

PS 2: Motion and stability: Forces and interactions

Ps 3: Energy

PS 4: Waves and their applications in technologies for information transfer

Life sciences

LS 1: From molecules to organisms: Structures and processes

LS 2: Ecosystems: Interactions, energy, and dynamics

LS 3: Heredity: Inheritance and variation of traits

LS 4: Biological evolution: Unity and diversity

\section{Earth and space sciences}

ESS 1: Earth's place in the universe

ESS 2: Earth's systems

ESS 3: Earth and human activity

Engineering, technology, and applications of science

ETS 1: Engineering design

ETS 2: Links among engineering, technology, science, and society 
the world" (NRC, 2012, p. 83). CCCs are a refinement of the common themes in Science for All Americans (AAAS, 1989) and the unifying concepts and processes in the National Science Education Standards (NRC, 1996).

DCIs highlight the fundamental science content students are expected to learn. DCIs meet some or all of the following criteria:

1. Have broad importance across multiple sciences or engineering disciplines or be a key organizing principle of a single discipline.

2. Provide a key tool for understanding or investigating more complex ideas and solving problems.

3. Relate to the interests and life experiences of students or be connected to societal or personal concerns that require scientific or technological knowledge.

4. Be teachable and learnable over multiple grades at increasing levels of depth and sophistication. That is, the idea can be made accessible to younger students but is broad enough to sustain continued investigation over years. (NRC, 2012, p. 31)

DCIs are organized into four disciplines: physical sciences; life sciences; Earth and space sciences; and engineering, technology, and applications of science. As DCIs provide explanatory power to make sense of phenomena, they depart from the traditional notion of science content consisting primarily of science concepts to be tested.

The third shift involves coherent learning progressions of student understanding over time, which occur across Grades K-12 as well as across shorter time frames, such as within a grade band, grade level, or science unit. Sustained opportunities to develop ideas over time offer advantages for science learning. The NGSS offer two main opportunities for learning progressions: (a) the NGSS identify learning progressions across the $\mathrm{K}-2,3-5,6-8$, and $9-12$ grade bands and (b) student learning progresses over the course of a year or unit, as lessons are designed to build coherently over time.

\section{$4 \quad$ Language Instructional Shifts}

Language instructional shifts, informed by contemporary views in secondlanguage learning, highlight language use for a particular purpose in a particular context. In the science classroom, all students, including ELs, make sense of phenomena and use language in service of learning science. The emphasis on using language to learn science in contemporary views differs from the emphasis on vocabulary (lexicon) and grammar (syntax) as a precursor or prerequisite to learn science in traditional views. Language instructional shifts include (a) using multiple modalities strategically, (b) using multiple registers 
by progressing from everyday to specialized registers, and (c) adapting modalities and registers across different types of interactions (see Table 2; for details, see Lee et al., 2013; Lee et al., 2019; NASEM, 2018).

First, students learn to use multiple modalities strategically. Modalities refer to the multiple and varied channels through which communication occurs. Multiple modalities include visual modalities (e.g., gestures, pictures, symbols, graphs, tables, and equations) and the linguistic modalities of talk (oral language) and text (written language; Lee et al., 2019). In science and engineering, multiple modalities, especially the visual variety, are essential meaning-making resources. In EL education, multiple modalities support ELs at the early stages of English language proficiency to engage in science and engineering practices that are language intensive, such as developing models, arguing from evidence, and constructing explanations. Thus, multiple modalities are essential to engagement in science and engineering practices and particularly beneficial to ELs (Grapin, 2019).

Second, students learn to use increasingly specialized registers of talk and text. Registers refer to the language used in talk and text that is associated with particular contexts of use (Biber \& Conrad, 2009). Registers can range from everyday to specialized. As students build science understanding over the course of instruction, their language use becomes increasingly specialized. This specialized register affords the precision necessary to communicate disciplinary meaning as students' science ideas become more sophisticated (Grapin et al., 2019; Quinn et al., 2012). In the science classroom, precision goes beyond the use of vocabulary to the communication of precise disciplinary meaning. In addition, precision does not imply linguistic accuracy. ELs can communicate precise disciplinary meaning using their emerging English.

Third, students learn to use multiple modalities and registers to meet communicative demands of different types of interactions. Which modalities and registers are used is determined, in part, by whether interactions are one to one (e.g., one student communicating with a partner), one to small group (e.g., one student communicating with a small group), one to many (e.g., one student communicating with the whole class), or small group to many (e.g., small groups making class presentations). In doing so, students move fluidly across modalities and registers to meet the communicative demands of different types of interactions. While one-to-one interactions allow students to check for comprehension in real time ("now") and space ("here") and clarify their meaning as needed, one-to-small group or one-to-many interactions do not always offer such opportunities. The specialized register affords the explicitness (e.g., fewer deictic words like "it" and "there") necessary to communicate disciplinary meaning across temporal (beyond "now") and physical (beyond "here") contexts. 


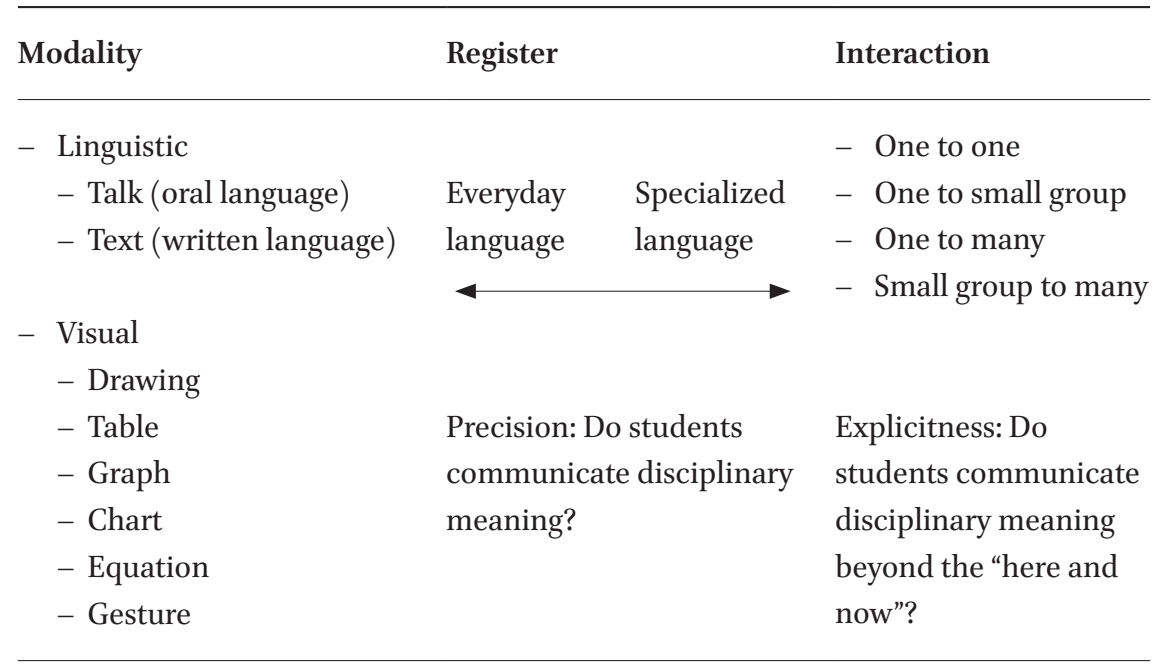

In promoting NGSS-aligned teaching and learning, the SAIL curriculum promotes language use in ways that science learning and language learning are mutually supportive of each other with all students and ELs in particular (Lee et al., 2019; NASEM, 2O18). In this section, how SAIL promotes rigorous science learning and rich language use with a focus on ELs is described.

\subsection{SAIL Curriculum}

SAIL consists of four units that address all of the 16 performance expectations (i.e., standards) for fifth grade, including six physical science performance expectations; two life science; five Earth and space science; and three engineering, technology, and applications of science. Each unit is anchored in a local phenomenon expressed in the form of a driving question:

Unit 1: What happens to our garbage? (matter in physical science)

Unit 2: Why did the tiger salamanders disappear? (ecosystems in life science)

Unit 3: Why does it matter if I drink tap water or bottled water? (Earth's systems in Earth science)

Unit 4: Why do falling stars fall? (space systems in space science) 
Each unit is intended for approximately one marking period of 9 weeks, assuming 40 minutes of science instruction three times per week. Each unit has approximately 10 lessons, with each lesson spanning typically two to four class periods for a total of $25^{-} 3$ o class periods per unit. SAIL consists of (a) teacher guide materials for classroom implementation, including front matter and detailed lesson plans; (b) student resources, including readings, investigation sheets, handouts, videos, assessments, and science and engineering notebooks; and (c) science supplies for all of the investigations. Each lesson includes the timeframe, three-dimensional learning performances, lesson overview, materials needed (e.g., readings and videos), and preparation tips.

\subsection{Science Instructional Shifts in SAIL Curriculum}

A unit of instruction starts with a phenomenon or problem that students generate with guidance from their teacher. This phenomenon leads to the driving question of the unit. Over the course of the unit, students generate a series of sub-questions as they build science understanding coherently over the course of the unit. To answer a sub-question, students engage in three-dimensional learning by blending SEPs, CCCs, and DCIs. Their new understanding, in turn, generates a new sub-question toward answering the driving question of the unit. Over the course of instruction, students develop deeper and more sophisticated understanding of science to make sense of the phenomenon of the unit.

To describe the three science instructional shifts, the first unit, "What happens to our garbage?" is described. Through rigorous external reviews by expert panels, Achieve, Inc., awarded the SAIL Garbage Unit the NGSs Design Badge, which is the highest rating for NGSS-aligned curriculum units. To date, this unit is one of only three elementary school units that have been awarded the NGSS Design Badge. It is also the only unit focused specifically on ELs. The Garbage Unit and supplementary materials are open-source resources available to the public at https://www.nextgenscience.org/resources/examples-quality-ngss -design. The other three units follow the same design principles as the Garbage Unit (see NASEM, 2018, Box 3-1 on pp. 64-65; visit the New York University sAIL Research Lab at https://www.nyusail.org/).

All Students, including ELs, Explain Phenomena or Design Solutions to Problems

SAIL uses local phenomena to capitalize on cultural and linguistic resources that diverse student groups bring to the science classroom while meeting their learning needs in developing science understanding. As the central goal of 
science is to make sense of phenomena, selection of phenomena is important with all students, especially those who have traditionally been marginalized in science and do not view science as real or relevant to their lives or future careers.

SAIL uses local phenomena or problems that involve everyday experience and language of all students, including ELs, in their homes and communities. Local phenomena or problems combine place-based learning and project-based learning (Lee, 2020; Lee et al., 2019). From an equity perspective, through place-based learning, students apply science and engineering to their daily lives in local contexts of home and community (Semkin \& Freeman, 2008; Smith, 2002). ELs also bring with them a vast array of cultural and community resources that help them make sense of phenomena or problems. From a science perspective, through project-based learning, students develop deep understanding of science, integrate science disciplines as needed to explain phenomena, and design solutions to problems in local contexts (Krajcik, 2015; Krajcik \& Czerniak, 2013). Thus, integration of place-based learning and project-based learning affords all students, including ELs, the opportunity to engage in authentic, relevant science that is closely connected to their home and community experiences.

In the SAIL Garbage Unit, the phenomenon is that the school, home, and neighborhood make large amounts of garbage every day. The driving question is then framed broadly, "What happens to our garbage?" To answer this driving question, students develop physical models of a landfill by creating "landfill bottles" as open systems and closed systems (see Figure 1). As the unit progresses, they use their landfill bottles to investigate a series of sub-phenomena toward answering the driving question. For example, when the landfill bottles start to smell, students ask, "What is that smell?" and engage in related investigations to explain the sub-phenomenon of smell in terms of the particle nature of matter/gas (this particular sub-phenomenon is elaborated in a later section).
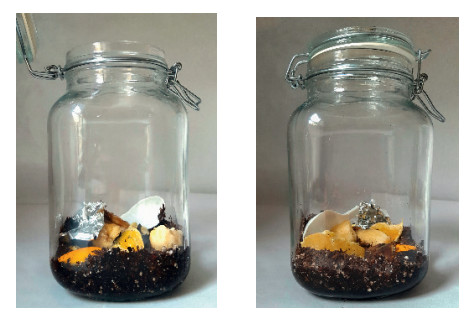

FIGURE 1

Open and closed landfill bottle systems for the SAIL

Garbage Unit 


\subsubsection{All Students, including ELs, Engage in Three-Dimensional Learning}

The Garbage Unit is designed to address four physical science performance expectations and introduces one life science performance expectation that is fully addressed in the subsequent ecosystems unit in fifth grade (see Table 3 ). For each performance expectation, each of the three dimensions of SEP, CCC, and DCI is identified.

SAIL promotes three-dimensional learning by blending SEPs, CCCs, and DCIs, which leads toward mastery of NGss performance expectations in fifth grade. For example, performance expectation 5-PS1-1 blends "develop a model to describe that" (SEP) "matter is made of particles" (DCI) "too small to see" (CCC).

In particular, SEPs are critical for all students, especially ELs (Lee et al., 2013; NASEM, 2018). Because SEPS are language intensive (e.g., develop and use models), they call for a high level of classroom discourse. ELs can carry out sophisticated science and engineering practices, such as constructing explanations and arguing from evidence, through their emerging English.

TABLE 3 Performance expectations addressed in the SAIL Garbage Unit

\section{Performance expectation}

\section{Physical science}

5-PS1-1. Develop a model to describe that (SEP) matter is made of particles (DCI) too small to see (CCC)

5-PS1-2. Measure and graph quantities to provide evidence that (SEP), regardless of the type of change that occurs when heating, cooling, or mixing substances (DCI), the total weight of matter (CCC) is conserved (DCI)

5-PS1-3. Make observations and measurements (SEP) to identify materials (DCI) based on their properties (CCC)

5-PS1-4. Conduct an investigation to determine (SEP) whether the mixing of two or more substances (DCI) results in (CCC) new substances (DCI)

\section{Life science}

5-LS2-1. Develop a model to describe (SEP) the movement of matter among (DCI) plants, animals, decomposers, and the environment (CCC; this performance expectation is partially addressed in the unit) 


\subsubsection{All Students, including ELs, Build Science Understanding over the} Course of Instruction

Lessons in a unit fit together coherently and build on each other as students investigate what happens to the garbage in their landfill bottle systems. Over the course of the 9-week unit, students answer a series of questions about garbage as they develop understanding of the targeted set of performance expectations (see Table 3). Over time, students develop deeper and more sophisticated understanding of the structure and properties of matter to make sense of the phenomenon and to answer the driving question, "What happens to our garbage?"

In the Garbage Unit (see Figure 2), students begin by observing properties of garbage materials and investigating what happens to garbage materials overt time (5-PS1-3 on properties of materials). When the landfill bottles start to smell in the open system, students ask, "What is that smell?" (5-PS1-1 on particle nature of matter/gas). They also ask, "What causes changes in the properties of materials in the garbage?" and "What causes smell from the garbage?" (5-PS1-4 on chemical reactions). They obtain information about microbes causing food materials to decompose and produce a smell (5-LS2-1 on decomposers in the environment). In addition, they make observations of the weight of the garbage materials when some materials (e.g., banana and orange) seem to have vanished (5-PS1-2 on conservation of weight of matter). Students learn that microbes cause food materials to decompose, which is also addressed in the subsequent ecosystems unit (5-LS2-1).

The storyline of the Garbage Unit is summarized in Figure 2. Students sort garbage materials into categories and look for patterns of garbage materials in different categories. They also sort garbage materials at home and look for patterns in different categories. In addition, they identify that the garbage system has sub-systems of school garbage, home garbage, and neighborhood garbage, which all go to a local landfill. The students observe that the school, home, and

What happens to our garbage?

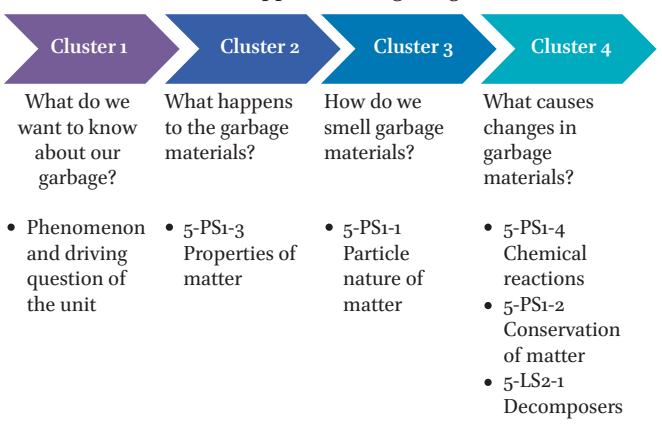

FIGURE 2

Sequence of instruction (or storyline) of the SAIL Garbage Unit 
neighborhood make large amounts of garbage every day. Then, they ask the driving question, "What happens to our garbage?" (Cluster 1).

Students make open and closed "landfill bottles" with banana and orange as food materials and aluminum foil and a plastic spoon as non-food materials (Figure 1). Over time, students observe changes in the properties of garbage materials in the open and closed landfill bottles. They also measure the weights of the open and closed bottles (Cluster 2).

After a few weeks, students measure the weight of the closed bottle. Although the food materials have vanished, the weight stays the same. Then, the students open the closed bottle and smell the garbage. Students explain that the smell is a gas made of particles that are too small to see and move freely to reach the nose (Cluster 3 ).

Students find out that microbes are causing food materials to decompose, and this life science core idea is partly addressed in the Garbage Unit and then fully addressed in the next unit on ecosystems. They explain that smell is a new substance when microbes decompose food materials. They also explain that in the closed landfill bottle, the weight of the garbage materials is conserved, even though the food materials seem to have vanished (Cluster 4).

\subsection{Language Instructional Shifts in SAIL Curriculum}

SAIL capitalizes on language learning opportunities and demands with all students, especially ELs. Over the course of instruction, students develop deeper and more sophisticated understanding of science to make sense of phenomena. As science understanding becomes more sophisticated, language use becomes more specialized. To communicate the sophistication of their ideas, all students, including ELs, use multiple modalities more strategically and more specialized registers across different types of interaction. To highlight the three language instructional shifts of modality, register, and interaction (see Table 2), we use the phenomenon of the smell of garbage (see Cluster 3 in Figure 2).

\subsubsection{ELs Learn to Use Multiple Modalities Strategically}

Throughout the Garbage Unit, students use multiple modalities to engage in SEPs. For example, they use tables to analyze and interpret data about the properties and weight of materials in the landfill bottles. They also develop models using a strategic combination of visual and written language modalities to explain the decrease in weight of the open landfill bottle system.

With regard to the smell of garbage in Cluster 3 , students learn to use multiple modalities more strategically to communicate the sophistication of their ideas about smell. As students develop models of smell, they use both 
visual (e.g., drawings, diagrams, and symbols) and linguistic (i.e., talk and text) modalities to communicate their ideas about smell.

Figure 3 shows two samples of a student's initial models of smell. Students' initial models typically include a cloud (to the left) or wavy lines (to the right) rather than particles. The model to the right includes both visual (drawing) and textual (written language) modalities, including a key with text ("Smells") to indicate the meaning of the wavy lines.

After engaging in a series of investigations about smell, students come to understand that gas is made of particles too small to see that are moving freely around in space. Figure 4 shows a sample revised model of smell represented with particles rather than wavy lines. Whereas the initial model used color somewhat arbitrarily (Figure 3), the revised model used color more strategically to distinguish between smell particles (in blue) and air particles (in red). The model also included arrows pointing in multiple directions to represent how smell and air particles are moving freely around in space. In conjunction with the visual modality (drawings and symbols), the textual modality (written language) was used to indicate smell and air particles as well as their movement.

In their final models of smell, students apply their understanding of the particle nature of gas to make sense of what is happening in their landfill bottles. Figure 5 shows a sample final model of the open landfill bottle system. Similar to the revised model of smell (Figure 4), this final model used both visual (drawings and symbols) and textual (written language) modalities to represent gas as made of particles too small to see that are moving freely around in space. The use of the color green to represent both the rotting food and the gas particles was strategic, as it communicated the crucial idea that matter
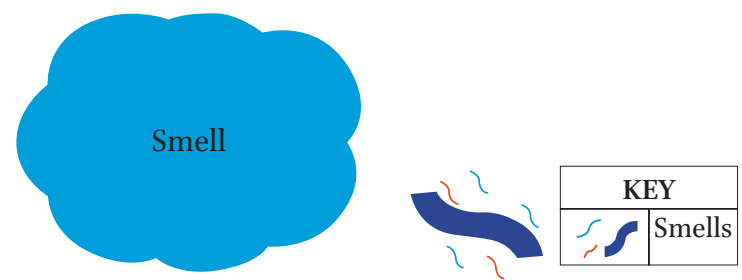

FIGURE 3 Sample initial models of smell

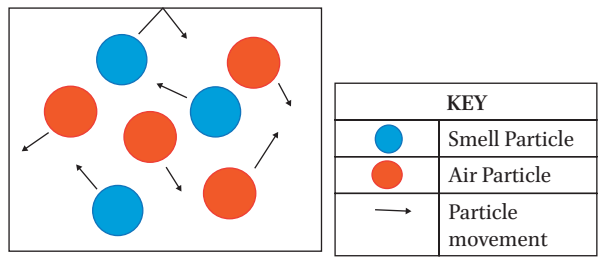




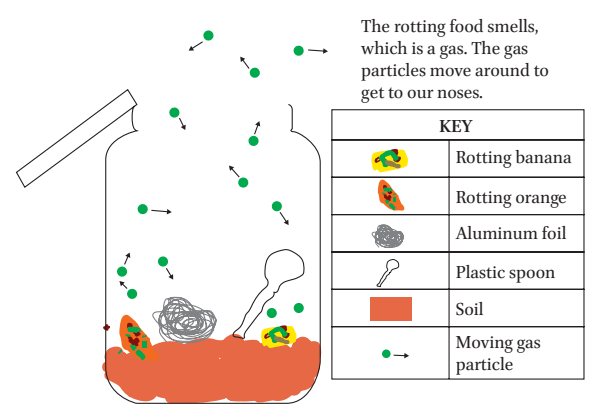

FIGURE 5

Sample final model of open landfill bottle system

that was once part of the food (solid) was now flowing out of the open system as smell (gas). The model also included text to communicate the relationship between smell and gas as well as how smell travels to the nose (see top right of the figure).

Over the course of Cluster 3, as students build their understanding of the particle nature of gas, they use visual (drawings and symbols) and textual (written language) modalities more strategically to represent the increasing sophistication of their ideas. While all students use multiple modalities to engage in developing models, ELs in particular benefit from opportunities to represent their science ideas by using their full range of meaning-making resources.

\subsubsection{ELs Learn to Use Increasingly Specialized Registers of Talk and Text}

Students draw on both everyday and specialized registers. When engaging in argument from evidence about changes in the type and amount of matter in the landfill bottles, students communicate precise disciplinary meaning by supporting their claims with evidence and reasoning. Students' language use also becomes more precise, as they learn that the level of precision needed to engage in SEPs demands a comparable level of precision in language use (Grapin et al., 2019; Lee et al., 2019). This demand for precision goes beyond vocabulary to the logic of connecting cause and effect and the validity of claims and evidence.

With regard to the smell of garbage in Cluster 3, when students first notice the smell coming from the open landfill bottles, they communicate their ideas using a more everyday register (e.g., "The smell stinks!"). They record their initial ideas about how the smell from the open landfill bottles travels across the room to their noses (e.g., "The smell is so strong. It comes to me and goes up my nose."). The opportunity to use all of their linguistic resources to experience and begin making sense of smell promotes inclusion of all students, including ELs, in the science classroom. 
At the midpoint of Cluster 3, as students engage in a series of investigations and build their understanding of the particle nature of gas, they transition to a more specialized register. For example, when students compress air in a syringe and feel pressure pushing back on the plunger, they need a more specialized register to communicate precisely about what is happening inside the syringe (e.g., "Gas particles too small to see are moving freely and bouncing off the surface of the plunger."). The phrase "too small to see" is precise about the scale at which gas particles can be observed. Similarly, the phrase "moving freely around in space" is precise about the movement of gas particles.

At the end of Cluster 3, students apply their understanding of smell to the landfill bottle investigation. They transition to a more specialized register to communicate precisely about the relationship between the rotting food in the landfill bottle and the smell it produces (e.g., "Matter that was part of the food is now moving freely out of the landfill bottle system as gas particles, but they are too small to see.").

Over the course of Cluster 3, as students build their understanding of the particle nature of gas, they use a more specialized register to communicate the increasing sophistication of their ideas. The specialized register goes beyond grammar and vocabulary (e.g., "particles") to the precise communication of ideas. A focus on precision is especially consequential for ELs, whose contributions should be valued for their disciplinary meaning rather than their linguistic accuracy. ELs communicate precise disciplinary meaning through their emerging English (e.g., "I can't see particle because too small" is precise despite grammatical inaccuracies).

\subsubsection{ELs Learn to Use Multiple Modalities and Registers to Meet Communicative Demands of Different Types of Interactions}

Students adapt their language to meet varying communicative demands of different types of interactions. As science often involves communicating about objects and events not immediately present, students' language use becomes more explicit. Explicitness makes language use more effective with "distant" audiences beyond "here" and "now." When planning the landfill bottle investigation in small groups (one-to-small group interaction), students use a more everyday register, as they can check for comprehension and clarify meaning in real time and space. When students share their arguments and explanations with the class (one-to-many interaction), they use a more specialized register, as this register affords the explicitness necessary to communicate beyond the "here and now."

With regard to the smell of garbage in Cluster 3, students use a range of modalities and registers across different types of interactions, including one-to-one interactions (e.g., sharing ideas with a partner about smell) and 
one-to-many interactions (e.g., reporting the results of an investigation to the whole class). They become more skilled in adapting their language to meet the communicative demands of different interactions. For example, working in partners (one to one), students engage with a computer simulation that models what is happening inside the syringe. Pointing to the particles on the screen, students use a more everyday register in conjunction with the visual modality (e.g., "Look at them move!"). A more everyday register is effective in this interaction because there is joint attention to a common focus (i.e., the computer screen), and students can request clarification in real time (e.g., "What moved?"). When the class comes together to share their observations (one to many), students have to use a more specialized register to make their meaning explicit in the absence of a shared frame of reference (e.g., "The particles were moving all around and bouncing off each other in different directions."). A more specialized register is effective in this interaction because of the explicitness this register affords for communicating beyond the here and now. When teachers support ELs to meet the communicative demands of different types of interactions, they promote ELs' meaningful participation in the science classroom.

How Science and Language Instructional Shifts Work Together

Science and language instructional shifts are mutually supportive of each other. Compelling phenomena rooted in everyday experiences promote access to science and inclusion of all students, including ELs, by allowing them to bring their cultural and linguistic resources (i.e., funds of knowledge) into the science classroom. Making sense of phenomena provides a reason to learn science and to communicate ideas with peers and the teacher (Science Instructional Shift 1).

To make sense of phenomena, students engage in three-dimensional learning by blending SEPs, CCCs, and DCIs (Science Instructional Shift 2). As they "do" science, they use language. While communicating ideas with peers and the teacher, students use multiple modalities, including both linguistic and nonlinguistic modalities (Language Instructional Shift 1). They also use registers, ranging from everyday to specialized (Language Instructional Shift 2). In addition, students participate in a range of different interactions (Language Instructional Shift 3).

Over the course of science instruction, students develop deeper and more sophisticated understanding of science, which helps them make sense of the phenomenon and answer the driving question of the unit (Science Instructional Shift 3). To communicate the sophistication of their ideas over 
the course of instruction, ELs use modalities more strategically (Language Instructional Shift 1) and a more specialized register (Language Instructional Shift 2). As ELs use language to do science in pair, small-group, and wholeclass settings, they learn to adapt their language to meet the communicative demands of different types of interactions (Language Instructional Shift 3).

\section{7 Conclusion}

Science and language instructional shifts highlight their mutually supportive nature with all students and ELs in particular. ELs use language purposefully in service of doing science in a classroom community. This is different from traditional views that ELs need English proficiency as a precursor or prerequisite to participating in the science classroom. As students make sense of a phenomenon (i.e., What happens to our garbage?), they engage in threedimensional learning by blending SEPs, CCCs, and DCIs. Over time, they develop increasingly sophisticated understanding of science (i.e., learning progressions). While "doing" science, students use language. They initially draw on a range of modalities (e.g., drawings, symbols, and written language) to communicate their ideas. As they build their science understanding over time, they become more strategic in using multiple modalities to represent the sophistication of their ideas. Also, students initially use a more everyday register to communicate their ideas. As they build their science understanding over time, they progress toward using a more specialized register to communicate the sophistication of their ideas with precision. In addition, students participate in different types of interactions typical of the science classroom. As these interactions demand different degrees of explicitness, students move fluidly across modalities and registers to meet varying communicative demands.

\section{8}

Implications

This article focuses on the Framework (NRC, 2012) and the NGSS, which provide the vision for science education with all students, including ELs, in the United States (Lee et al., 2015; NGSS, 2013b). The 9.6\%, or 4.9 million students, of the pre-K-12 public school student population who are non-native English speakers in the United States (National Center for Education Statistics, 2019) are referred to by different labels, including ELs, which is the term used in federal legislation since the Every Student Succeeds Act of 2015, such as English language learners, emergent bilinguals, multilingual learners, and emergent 
multilingual learners. These students are served though a wide range of language instruction models, including English as a second language (ESL), content-based ESL, sheltered instruction, traditional bilingual education, developmental bilingual education, two-way dual language immersion, and newcomer (see Table 2.1 in NASEM, 2018, pp. 35-37). The conceptual framework guiding the SAIL curriculum is applicable across these varied language instruction models (see Chapters 3 and 4 in NASEM, 2018, pp. 55-141).

In addition to its use with various models of language instruction, this conceptual framework has implications for science and language instruction with second or foreign language learners in other countries, including those in the Asia-Pacific region. The conceptual framework starts with what counts as science learning. In the United States, the vision of science learning is based on the Framework (NRC, 2012), which guided the development of the NGSS for all students (Lee et al., 2015; NGSS Lead States, 2013a, 2013b). Contemporary views on knowledge-in-use in science learning highlight "what science knowledge does" (i.e., use science ideas to make sense of phenomena and problems), rather than "what science knowledge is" (i.e., a mastering of canonical knowledge of science disciplines).

In a similar manner, this conceptual framework defines what counts as language learning with second-language learners. In the United States, the vision of second-language learning is based on English Learners in STEM Subjects (NASEM, 2018). Contemporary views on language-in-use in second-language learning highlight "what language does" (i.e., use language for a particular purpose in a particular setting), rather than "what language is" (i.e., a mastering of grammar and vocabulary).

Contemporary views on using language to learn science and learning language as a product differ from traditional views on language, specifically vocabulary (lexicon) and grammar (syntax) as a precursor or prerequisite to learning science. As students use language to do science, they develop their science understanding and language proficiency in tandem. These contemporary views on science learning, language learning, and integrating science and language learning are applicable across science instruction programs, language instruction programs, and language groups.

\section{Abbreviations}

AAAS American Association for the Advancement of Science

CCCs Crosscutting Concepts

DCIs Disciplinary Core Ideas

ELs English Learners 
ESL English as a Second Language

LS Life Sciences

NASEM National Academies of Sciences, Engineering, and Medicine

NGSS Next Generation Science Standards

NRC National Research Council

PS Physical Sciences

SAIL Science And Integrated Language

SEPS Science and Engineering Practices

\section{Funding}

This study is supported by the National Science Foundation (NSF; Grant No. DRL-1503330). Any opinions, findings, conclusions, or recommendations expressed in this publication are those of the authors and do not necessarily reflect the position, policy, or endorsement of the funding agency.

\section{Ethical Considerations}

The data reported in this study does not require human subjects' approval.

\section{About the Author}

Okhee Lee is a professor in the Steinhardt School of Culture, Education, and Human Development at New York University. Her research areas include science education, language and culture, and teacher education. She was a member of the NGSS writing team and served as leader for the NGSS Diversity and Equity Team. She was also a member of the Steering Committee for the Understanding Language Initiative at Stanford University.

\section{References}

American Association for the Advancement of Science. (1989). Sciencefor all Americans. Oxford University Press.

American Association for the Advancement of Science. (1993). Benchmarks for science literacy. Project 2061. Oxford University Press. 
Biber, D., \& Conrad, S. (2009). Register, genre, and style. Cambridge University Press. Grapin, S. E. (2019). Multimodality in the new content standards era: Implications for English learners. TESOL Quarterly, 53 (1), 30-55. https://doi.org/10.1002/tesq.443.

Grapin, S. E., Llosa, L., Haas, A., Goggins, M., \& Lee, O. (2019). Precision: Toward a meaning-centered view of language use with English learners in the content areas. Linguistics and Education, 50 (1), 71-83. https://doi.org/10.1016/j.linged.2019.03.004.

Harris, C. J., Krajcik, J. S., Pellegrino, J. W., \& McElhaney, K. W. (2016). Constructing assessment tasks that blend disciplinary core ideas, crosscutting concepts, and science practice for classroom formative applications. SRI International.

Kibler, A., Valdés, G., \& Walqui, A. (2014). What does standards-based educational reform mean for English language learner populations in primary and secondary schools? TESOL Quarterly, 48 (3), 433-453. https://doi.org/10.1002/tesq.18.

Krajcik, J. (2015). Three-dimensional instruction: Using a new type of teaching in the science classroom. The Science Teacher, 82 (8), 50-52. https://mydigitalpublication .com/publication/?i=276015\&article_id=2292808\&view=articleBrowser.

Krajcik, J. S., \& Czerniak, C. (2013). Teaching science in elementary and middle school classrooms: A project-based approach (4th ed.). Routledge.

Larsen-Freeman, D. (2007). Reflecting on the cognitive-social debate in second language acquisition. The Modern Language Journal, 7, 773-787.

Lee, O. (2020). Making everyday phenomena phenomenal: Using phenomena to promote equity in science instruction. Science and Children, $5^{8}(1), 5^{6-61}$. https://www .nsta.org/science-and-children/science-and-children-septemberoctober-2020/ making-everyday-phenomena.

Lee, O., Llosa, L., Grapin, S. E., Haas, A., \& Goggins, M. (2019). Science and language integration with English learners: A conceptual framework guiding instructional materials development. Science Education, 103 (2), 317-337. https://doi.org/10.1002/ sce.21498.

Lee, O., Miller, E., \& Januszyk, R. (Eds.). (2015). NGSS for all students. National Science Teachers Association.

Lee, O., Quinn, H., \& Valdés, G. (2013). Science and language for English language learners in relation to Next Generation Science Standards and with implications for Common Core State Standards for English language arts and mathematics. Educational Researcher, 42 (4), 223-233. https://doi.org/10.3102\%2Foo13189X13480524.

National Academies of Sciences, Engineering, and Medicine. (2018). English learners in STEM subjects: Transforming classrooms, schools, and lives. National Academies Press.

National Center for Education Statistics. (2019). The condition of education 2019 (NCES 2019-144). U.S. Department of Education. http://nces.ed.gov/pubsearch/pubsinfo .asp?pubid $=2019144$. 
National Research Council. (1996). National science education standards. National Academies Press.

National Research Council. (2000). Inquiry and the national science education standards: A guide for teaching and learning. National Academies Press.

National Research Council. (2012). A framework for K-12 science education: Practices, crosscutting concepts, and core ideas. National Academies Press.

Next Generation Science Standards Lead States. (2013a). Next Generation Science Standards: For states, by states. Appendix A - Conceptual shifts in the Next Generation Science Standards. https://www.nextgenscience.org/resources/ngss-appendices.

Next Generation Science Standards Lead States. (2013b). Next Generation Science Standards: For states, by states. Appendix D - All standards, all students: Making the NGSS accessible to all students. https://www.nextgenscience.org/sites/default/files/ Appendix\%2oD\%2oDiversity\%2oand\%2oEquity\%206-14-13.pdf.

Quinn, H., Lee, O., \& Valdés, G. (2012). Language demands and opportunities in relation to Next Generation Science Standards for English language learners: What teachers need to know. Stanford University, Understanding Language Initiative.

Semkin, S., \& Freeman, C. B. (2008). Sense of place in the practice and assessment of place-based science teaching. Science Education, 92, 1042-1057. https://doi.org/10 $.1002 /$ sce.20279.

Smith, G. A. (2002). Place-based education: Learning to be where we are. Phi Delta Kappan, 83 (8), 584-594. https://doi.org/10.1177\%2Foo3172170208300806.

Valdés, G. (2015). Latin@s and the intergenerational continuity of Spanish: The challenges of curricularizing language. International Multilingual Research Journal, 9 (4), 253-273. https://doi.org/10.108o/19313152.2015.1086625.

Zuengler, J., \& Miller, E. (2006). Cognitive and sociocultural perspectives: Two parallel SLA worlds? TESOL Quarterly, 40 (1), 35-58. http://faculty.educ.ubc.ca/norton/ Zuengler\%2oMiller\%2020o6\%2op.pdf. 